\title{
Comparativo entre concreto protendido $\in$ convencional: estudo de caso
}

\begin{tabular}{c}
\hline GUILHERME ALMEIDA MARTINS - Engenheiro Civil \\
\hline BRUNO CARRILHO DE CASTRO - Dr. Prof. \\
\hline DANIEL IGLESIAS DE CARVALHO - Me. Prof. \\
Universidade Federal do Tocantins
\end{tabular}

\section{RESUMO}

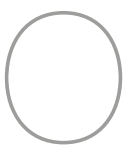

artigo trata da análise estrutural das longarinas das pontes sobre o Ribeirão Brejo Comprido, localizada em Palmas, para o concreto armado e o concreto protendido, tendo em vista a comparação de custos de insumos, equipamentos e mão de obra.

\section{INTRODUÇ̃̃O}

O concreto protendido quando usado nas longarinas das pontes, com o intuito de vencer grandes vãos, tem como vantagens a redução da seção transversal da viga, principalmente sua altura, assim como menores quantidades de aço e de concreto, com um menor peso próprio. Outro ponto positivo é o uso mais eficiente de materiais de alta resistência, se comparado ao concreto armado convencional.

No que se refere ao vão a ser vencido pelas longarinas, existe uma faixa de vão recomendado para cada tipo de material, técnica construtiva, seção transversal, tempo de execução da obra, dentre outros aspectos, que, se somados, retornam o custo do empreendimento e sua viabilidade econômica. Observa-se que as pontes nas quais suas longarinas são projetadas para vencer vãos maiores, requerem investimentos menores nos elementos da mesoestrutura e infraestrutura, como apresenta a Figura 1.

Por conseguinte, cabe ao engenheiro responsável ponderar os mais diversos aspectos que envolvem o custo de uma ponte. Qual o tipo de material mais adequado no uso dos elementos

estruturais? Na região onde a ponte será construída, existe a disponibilidade de mão de obra especializada? Qual o tempo de execução da obra? Qual o custo de manutenção da ponte? Esses questionamentos ajudam a ordenar um pensamento sistemático, dando forma a realidade que o engenheiro cidadão enfrenta no desenvolvimento de suas atividades junto à sociedade.

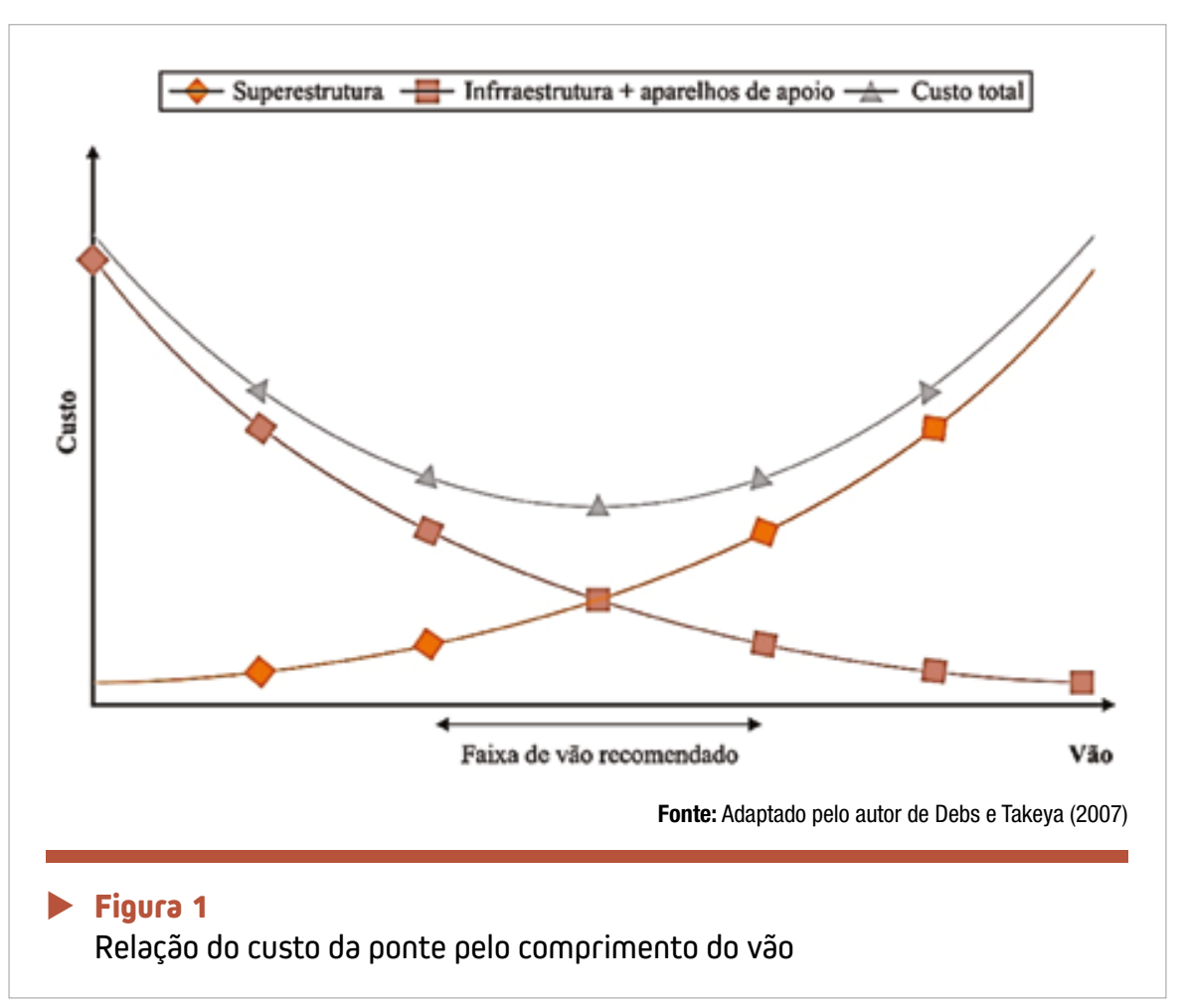

Figura 1

Relação do custo da ponte pelo comprimento do vão 
Logo, este estudo busca comparar o uso do concreto protendido nas vigas principais da ponte sobre o Ribeirão Brejo Comprido, bem como analisar as variações na seção transversal e no custo em relação ao concreto armado convencional. Portanto, é apresentado o projeto da ponte existente e seu sistema estrutural. Em seguida um projeto básico das longarinas de concreto protendido e concreto armado, com seus respectivos parâmetros de cálculo. Por fim, foi realizada uma comparação dos custos do uso de cada material em relação à seção transversal das longarinas.

Este estudo de caso visa colaborar com os profissionais da área da construção civil e infraestrutura, bem como apresentar aos servidores dos órgãos públicos uma ponderação a respeito dos custos desses dois materiais, seja para tomada de decisões em projetos futuros, seja acumular conhecimento técnico.

\section{PONTE SOBRE O RIBEIRÃO BREJO COMPRIDO}

Este artigo tem como objeto de análise as longarinas que compõem a estrutura das pontes sobre o Ribeirão Brejo Comprido localizada na cidade de Palmas, estado do Tocantins. Por sua vez, as pontes integram a obra de pavimentação asfáltica da Avenida NS-15, que liga a TO-010 à Avenida LO-13, como mostra a Figura 2. No estudo em questão, foram levantados os projetos das pontes junto a Secretaria de Infraestrutura do Estado do Tocantins (SEINFRA), com a devida autorização da Agência Tocantinense de Transporte e Obras (AGETO) para o estudo em questão.

O empreendimento contempla duas pontes de concreto armado, situadas na estaca 39+12,00 da pista da direita da AV NS 15 Norte. Suas di-

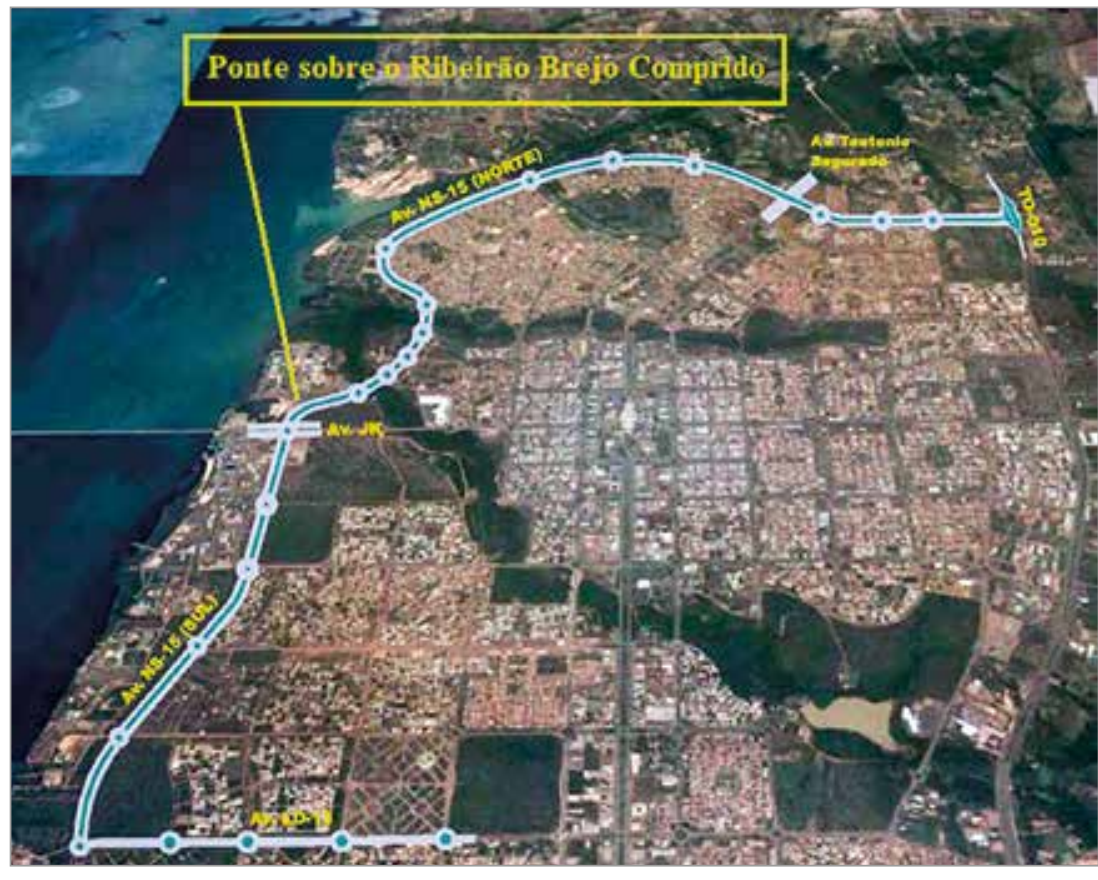

Fonte: Adaptado pelo autor de AGETO (2015)

Figura 2

Avenida NS - 15 mensões são 66,00 m de comprimento por $15,45 \mathrm{~m}$ de largura, com vão de $19,00 \mathrm{~m}$ e dois balanços de 4,50 m, como mostra o croqui da Figura 3.

$\mathrm{Na}$ seção transversal da ponte, têm-se três longarinas apoiadas so- bre as transversinas, com 10,50m de largura, para a pista de rodagem entre os guarda-rodas, e 4,00m de largura, para a ciclovia, totalizando $15,45 \mathrm{~m}$ de largura, conforme as Figuras 4,5 e 6 .

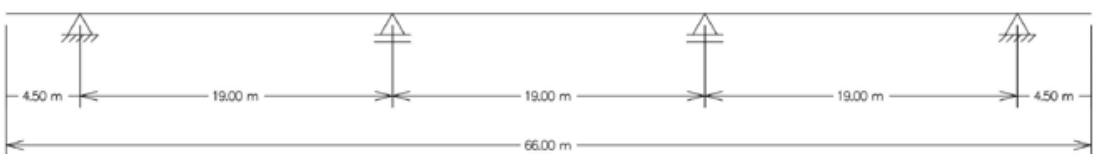

Fonte: Elaborado pelo autor

Figura 3

Sistema estrutural longitudinal para as longarinas

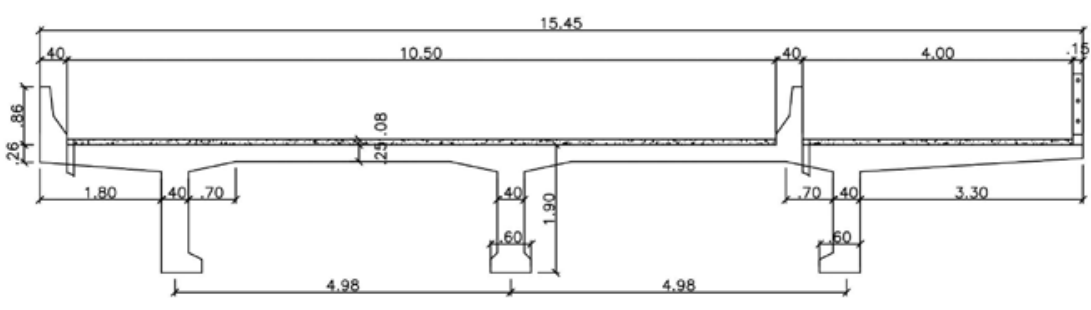

Fonte: Adaptado pelo autor de AGETO (2015)

Figura 4

Seção transversal da superestrutura 


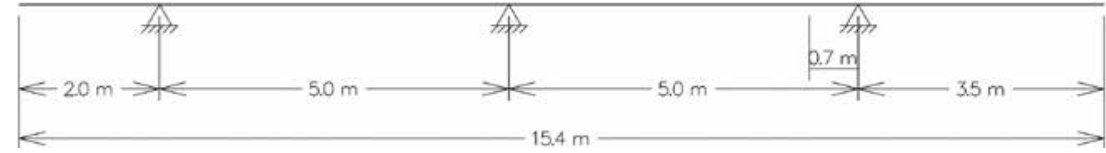

Fonte: Elaborado pelo autor

\section{Figura 5}

Sistema estrutural transversal para as longarinas

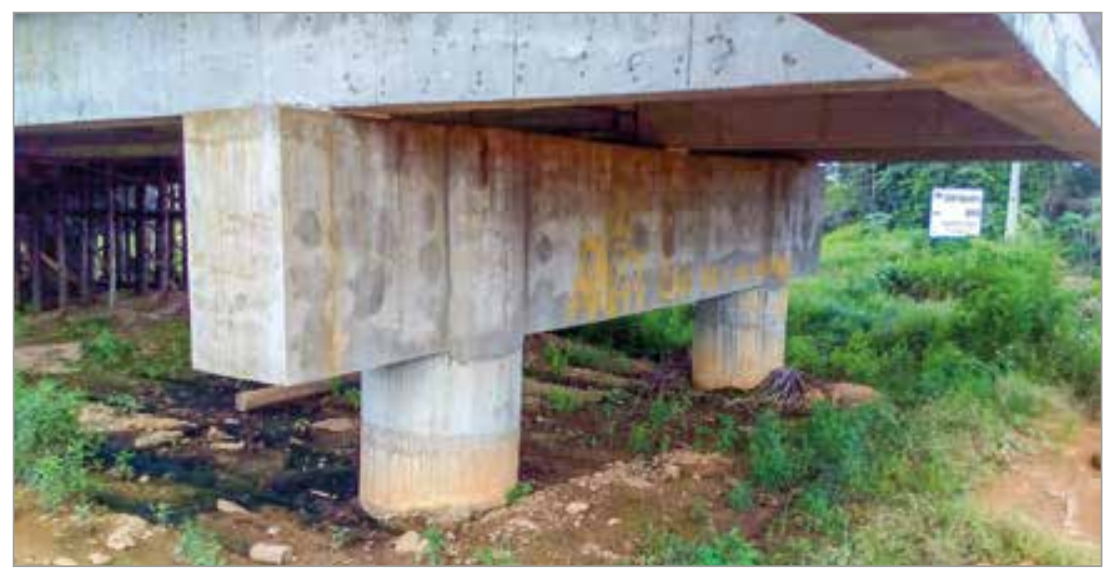

Fonte: Autor

Figura 6

Detalhe do apoio da longarina sobre a transversina

\section{LONGARINAS DE CONCRETO ARMADO E CONCRETO PROTENDIDO}

Com os projetos em mãos, foram examinadas as características da estrutura, como o comprimento e largura da ponte, sistema estrutural empregado, classe da ponte, o trem-tipo adotado e a resistência característica do concreto utilizado nas longarinas. Em seguida, foi proposto um projeto básico das longarinas de concreto protendido e concreto armado. Para tanto, as vigas principais foram modeladas com as mesmas considerações do veículo tipo e as ações permanentes similares a do projeto original, valendo-se de uma seção transversal retangular (Tabela 2). Também foi mantido o sistema estrutural, por exemplo: o comprimento das longarinas, o posicionamento e tipo de apoio.

As ações provenientes das cargas móveis foram calculadas conforme preconiza a NBR 7188 (ABNT, 2013) que define as pontes como "estrutura sujeita a ação de carga em movimento, com posicionamento variável, [...] utilizada para transpor um obstáculo natural (rio, córrego ou vale)". Esta variação do posicionamento do veículo e sua influência na estrutura da ponte é comumente conhecida como "trem-tipo", e este deve ser posicionado de forma a assumir a posição mais desfavorável, inclusive nas faixas de segurança ou nos acostamentos.

Tabela 1 - Veículo-tipo TB - 450

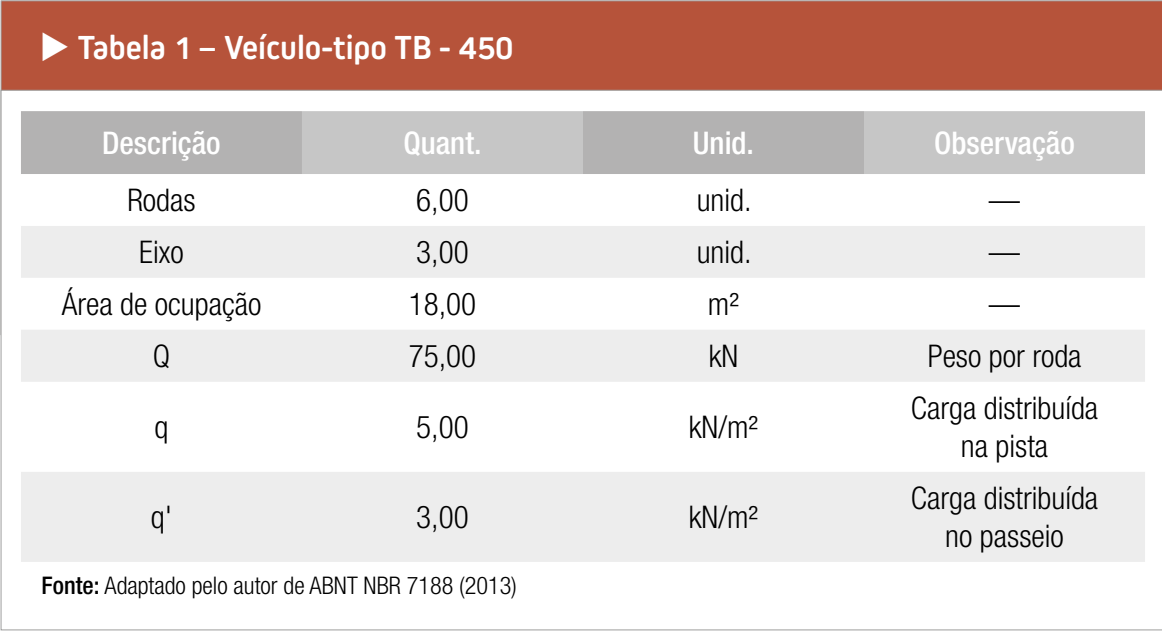

No cálculo do trem-tipo, foi adotado o veículo tipo TB-450, com seis rodas $P$ de $75 \mathrm{kN}$, três eixos de carga afastados entre si em 1,5m, com área de ocupação de $18 \mathrm{~m}^{2}$, circundada por uma carga uniforme distribuída constante $\mathrm{p}$ de $5 \mathrm{kN} / \mathrm{m}^{2}$ (NBR 7188, 2013).

Com o veículo-tipo definido e seus respectivos valores de forças verticais, foi calculada a carga concentrada $Q$ e a carga distribuída q, apresentadas na Tabela 1 e o trem-tipo apresentado na Figura 7.

As longarinas foram calculadas conforme preconiza a NBR 6118 (ABNT, 2014) e seus parâmetros de dimensionamento são apresentados na Tabela 3. Essa norma aborda as vigas como elementos lineares em que a flexão é preponderante e define o concreto com armadura ativa pós-tracionada, sem aderência, como um "concreto protendido em que o pré-alongamento da armadura ativa é realizado após o endurecimentodo concreto, sendo utilizadas, como apoios, partes do próprio elemento estrutural, mas não sendo criada aderência com o concreto, ficando a armadura ligada ao concreto apenas em pontos localizados". Os parâmetros de protensão são apresentados na Tabela 4.

Segundo NBR 6118 (ABNT, 2014), o objetivo da protensão nas condições 
de serviço é impedir ou limitar a fissuração e os deslocamentos dos elementos estruturais, bem como favorecer o meIhor aproveitamento de aços de alta resistência no estado-limite último (ELU). Essa norma ainda aborda as hipóteses básicas na análise dos esforços resistentes da seção da viga a serem consideradas. São elas: (a) as seções transversais se mantêm planas após a deformação; (b) a deformação das barras passivas aderentes ou o acréscimo de deformação das barras ativas aderentes em tração ou compressão deve ser a mesma do concreto em seu entorno; (c) as tensões de tração no concreto, normais à seção transversal, devem ser desprezadas no ELU.

No dimensionamento das longarinas de concreto protendido, a tensão utilizada na protensão adotada foi igual a soma das tensões resultantes do peso próprio, acrescidas 30\% das tensões resultantes da carga móvel, conforme a equação (1). Para o desenho do croqui das longarinas de concreto protendido foi adotado um cabo equivalente que representa a união de todos os cabos de protensão, conforme as Figura 8 e 9 .

$\sigma_{p}=\sigma_{p p}+30 \% \cdot \sigma_{c m}$

$\sigma_{\mathrm{p}}-$ Tensão de protensão;

$>\sigma_{\mathrm{pp}}-$ Tensão resultante do peso próprio da viga;

$\sigma_{\mathrm{cm}}-$ Tensão resultante da carga móvel.

\section{ANÁLISE DE CUSTO}

Na análise do custo da longarina, foi realizado um levantamento dos quantitativos de equipamentos, material e mão de obra para a execução das longarinas, tanto de concreto armado quanto de concreto protendido, con-

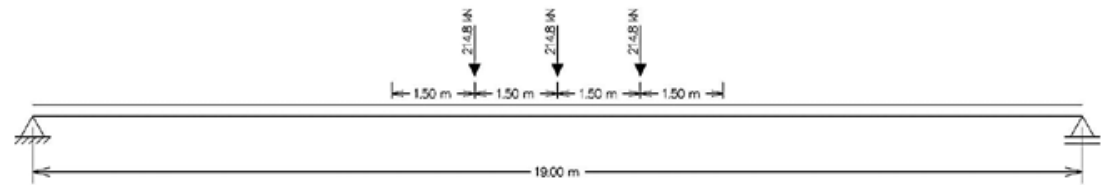

Fonte: Elaborado pelo autor

Figura 7

Trem-tipo viga 2, trecho 2

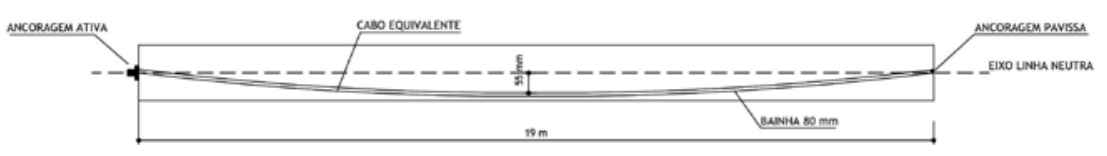

Fonte: Autor

Figura 8

Croqui do cabo equivalente

forme o diagrama da Figura 10. Ademais, como critério de medição para o volume de concreto, multiplicou-se a área da seção transversal pelo comprimento da viga.

No que se refere aos custos dos equipamentos, esses foram medidos em horas, já contidos nos seus coeficientes, bem como os custos de manutenção, operação e depreciação. Para a armadura ativa, foi adotado a cordoalha de 15,2 mm com peso próprio de
$1,126 \mathrm{kgf} / \mathrm{m}$, como força normal de protensão admissível de 196,1 kN, já inclusas as perdas de 1\%. Algumas considerações no levantamento do quantitativo são: 5\% de perdas para as formas; $10 \%$ de perdas para o quantitativo de aço. A armadura passiva foi medida pela a massa em quilogramas, adotando a massa específica de $7850 \mathrm{~kg} / \mathrm{m}^{3}$.

A base de cálculo dos custos diretos foi o Sistema de Custos Referenciais de Obras (SICRO) do Departamento

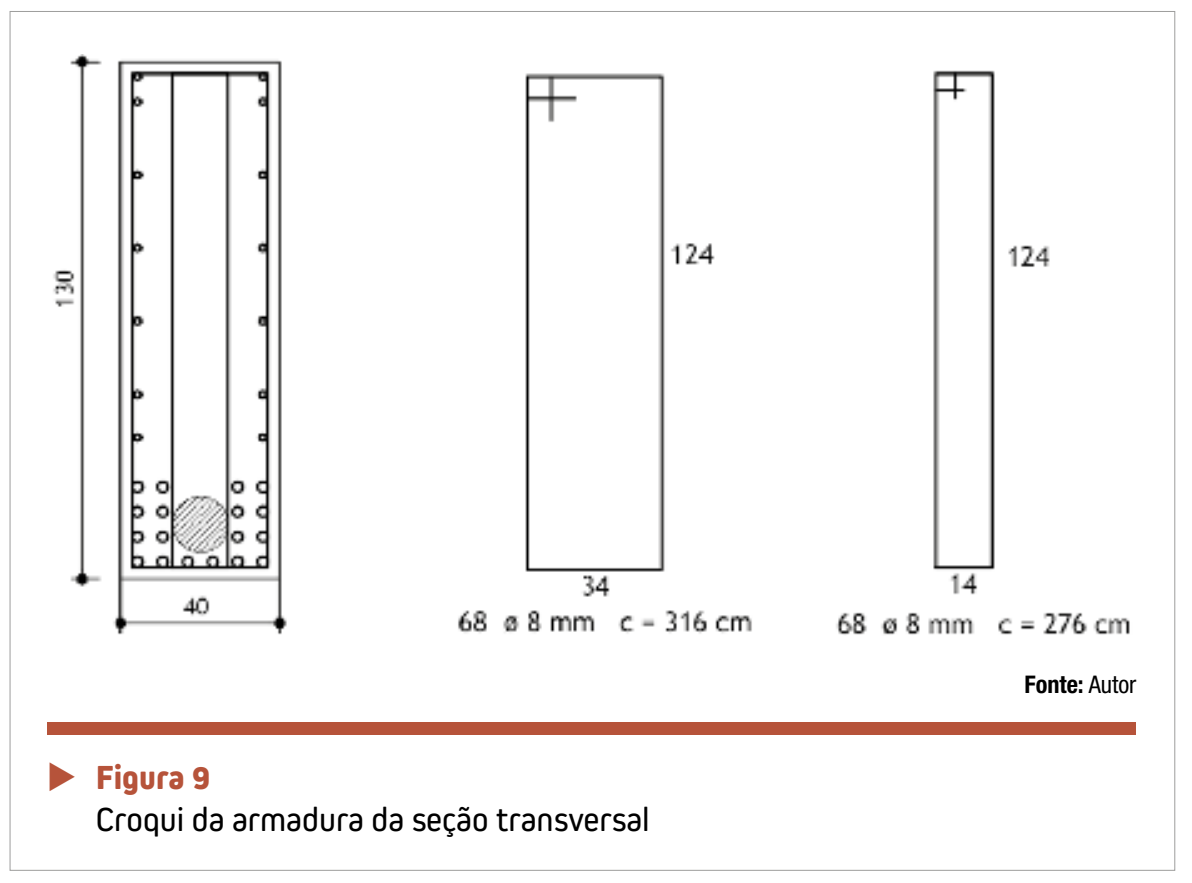


Nacional de Infraestrutura e Transportes (DNIT), relativo ao mês de março do ano de 2017, para a região norte, estado do
Tocantins. Como resultado, tem-se o custo direto da longarina para os dois tipos de material, apresentado no Qua-

\section{Tabela 2 - Seção transversal das longarinas}

\begin{tabular}{|c|c|c|c|c|}
\hline Descrição & C.A. & C.P. & Unid. & Observação \\
\hline b & 60 & 40 & $\mathrm{~cm}$ & Base \\
\hline h & 190 & 130 & $\mathrm{~cm}$ & Altura \\
\hline$Y_{c g}$ & 95 & 65 & $\mathrm{~cm}$ & - \\
\hline W & 361000 & 112667 & $\mathrm{~cm}^{3}$ & $\begin{array}{l}\text { Módulo } \\
\text { resistente }\end{array}$ \\
\hline I & 34295000 & 7323333 & $\mathrm{~cm}^{4}$ & $\begin{array}{l}\text { Momento } \\
\text { de inércia }\end{array}$ \\
\hline $\mathrm{Kc}$ & 32 & 22 & $\mathrm{~cm}$ & Raio resistente \\
\hline S & 11400 & 5200 & $\mathrm{~cm}^{2}$ & Área \\
\hline$d$ & 180 & 120 & $\mathrm{~cm}$ & Altura útil \\
\hline$d^{\prime}$ & 10 & 10 & $\mathrm{~cm}$ & - \\
\hline$\delta$ & 0,06 & 0,08 & - & - \\
\hline
\end{tabular}

dro 1 (referente ao concreto armado) e no Quadro 2 (referente ao concreto protendido). Nos quadros são descritos os serviços a serem executados com seus respectivos custos do material, mão de obra e equipamento, concomitantemente os respectivos subtotais e o custo final.

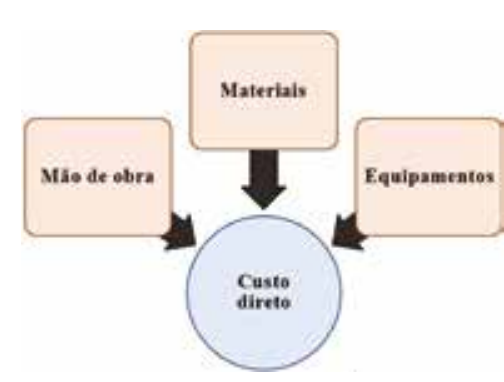

Fonte: Elaborado pelo autor

Figura 10 Composição do custo direto do serviço

Tabela 3 - Parâmetros de dimensionamento

\begin{tabular}{|c|c|c|c|c|}
\hline Descrição & C.A. & C.P. & Unid. & Observação \\
\hline$\alpha_{c}$ & 0,85 & 0,85 & - & $\mathrm{f}_{\mathrm{ck}} \leq 50 \mathrm{MPa}$ \\
\hline$f_{c k}$ & 2,50 & 4,50 & $\mathrm{kN} / \mathrm{cm}^{2}$ & Resistência característica do concreto \\
\hline$Y_{c}$ & 1,40 & 1,40 & - & Coeficiente de ponderação do concreto \\
\hline$f_{c d}$ & 1,79 & 3,21 & $\mathrm{kN} / \mathrm{cm}^{2}$ & Resistência de cálculo do concreto \\
\hline$f_{b d}$ & 0,62 & 0,91 & & $\mathrm{f}_{\mathrm{ck}} \leq 50 \mathrm{MPa}$ \\
\hline$\sigma_{c d}$ & 1,52 & 2,73 & $\mathrm{kN} / \mathrm{cm}^{2}$ & Máxima tensão de compressão do concreto \\
\hline$Y_{s}$ & 1,15 & 1,15 & - & Coeficiente de ponderação do aço \\
\hline $\mathrm{f}_{\mathrm{yk}}$ & 50,00 & 50,00 & $\mathrm{kN} / \mathrm{cm}^{2}$ & Coeficiente de ponderação do aço CA-50 \\
\hline$f_{y d}$ & 43,48 & 43,48 & $\mathrm{kN} / \mathrm{cm}^{2}$ & Resistência de cálculo do aço \\
\hline$\xi_{\lim }$ & 0,45 & 0,35 & - & $\mathrm{f}_{\mathrm{ck}} \leq 35 \mathrm{MPa}$ \\
\hline$\lambda$ & 0,80 & 0,80 & - & $\mathrm{f}_{\mathrm{ck}} \leq 50 \mathrm{MPa}$ \\
\hline$\lambda \cdot \xi_{\lim }$ & 0,36 & 0,28 & - & - \\
\hline$\mu_{\mathrm{lim}}$ & 0,30 & 0,24 & - & Momento limite reduzido \\
\hline$Y_{g}$ & 1,30 & 1,30 & - & Coeficiente de ponderação \\
\hline$\rho_{\text {min }}$ & 0,15 & 0,15 & $\%$ & Taxa mínima de armadura — Flexão \\
\hline$\rho_{w, \min }$ & 0,10 & 0,10 & $\%$ & Taxa mínima de armadura — Cortante \\
\hline$\alpha_{v}$ & 0,90 & 0,82 & - & - \\
\hline$\tau_{\mathrm{wu}}$ & 0,43 & 0,71 & $\mathrm{kN} / \mathrm{cm}^{2}$ & Tensão limite — Cortante \\
\hline$\tau_{\mathrm{c}}$ & 0,17 & 0,25 & $\mathrm{kN} / \mathrm{cm}^{2}$ & - \\
\hline $\mathrm{E}_{\mathrm{s}}$ & 20000,00 & 20000,00 & $\mathrm{kN} / \mathrm{cm}^{2}$ & - \\
\hline$\sigma_{\mathrm{sd}}$ & 43,00 & 43,48 & $\mathrm{kN} / \mathrm{cm}^{2}$ & $\mathrm{f}_{\mathrm{ck}} \leq 35 \mathrm{MPa}$ \\
\hline
\end{tabular}




\begin{tabular}{|c|c|c|c|}
\hline Descrição & Quant & Unid. & Observação \\
\hline$Y_{g}$ & 1,30 & - & $\begin{array}{l}\text { Coeficiente de ponderação } \\
\text { para as ações agrupadas }\end{array}$ \\
\hline$Y_{c g}$ & 0,65 & m & - \\
\hline $\mathrm{e}$ & 0,55 & $\mathrm{~m}$ & Excentricidade do cabo equivalente \\
\hline $1 / \mathrm{S}$ & 1,92 & $m^{2}$ & - \\
\hline e/W & 4,88 & $m^{2}$ & - \\
\hline$\% \sigma$ & $30 \%$ & - & $\begin{array}{l}\text { Percentual das tensões da carga } \\
\text { móvel a ser protendida }\end{array}$ \\
\hline $\mathrm{N}_{\mathrm{c}}$ & 196,10 & kN/cordoalha & Cordoalha de 15,2 mm \\
\hline$C_{p}$ & 4,00 & Unid. & Quantidade de cabos de protensão por viga \\
\hline
\end{tabular}

\section{RESULTADOS}

Os resultados apresentados no Quadro 1 e no Quadro 2 revelam um acréscimo de 13\% no custo direto das longarinas de concreto protendido, correspondendo a um valor de aproximadamente $\mathrm{R} \$ 60.000,00$. Fica evidente que o item de ancoragem ativa da longarina de concreto protendido onerou de forma significativa o custo do uso deste material, correspondendo a 20\% do total, como se observa na Figura 11, seguido do item de cordoalha com $12 \%$. É interessante notar que, para o custo dos itens de aço (armadura passiva), concreto e fôrmas, o custo do concreto protendido foi menor, principalmente para o uso do aço (armadura passiva), com uma diferença de 34\%.

Outro ponto que merece destaque é o comparativo de insumos, que é meIhor compreendido na Figura 12. Nos insumos, os custos de equipamentos tiveram pouca diferença. Todavia, para os custos referente à mão de obra, observa-se um aumento de 11\% para o concreto armado. Não obstante, os custos de materiais tiveram um salto de $13 \%$, sendo que essa diferença pode ser justificada pelos custos da ancoragem ativa e das cordoalhas do concreto protendido.

Do mesmo modo, outra comparação que se fez pertinente é relativa ao volume e à resistência características do concreto para cada método construtivo. No caso do concreto armado convencional, a longarina foi dimensionada com o $f_{c k}$ de $25 \mathrm{MPa}$ e seção transversal retangular de $60 \times 190 \mathrm{~cm}$, enquanto a longarina de concreto protendido foi dimensionada com $f_{c k}$ de $45 \mathrm{MPa}$ e seção transversal

\section{Quadro 1 - Orçamento da longarina de concreto armado}

\begin{tabular}{|c|c|c|c|c|c|c|c|c|c|c|}
\hline \multirow[t]{2}{*}{ Item } & \multirow[t]{2}{*}{ Descrição } & \multirow[t]{2}{*}{ Unid. } & \multirow[t]{2}{*}{ Quant. } & \multicolumn{2}{|c|}{ Preço material } & \multicolumn{2}{|c|}{$\begin{array}{l}\text { Preço mão } \\
\text { de obra }\end{array}$} & \multicolumn{2}{|c|}{$\begin{array}{l}\text { Preço } \\
\text { equipamento }\end{array}$} & \multirow{2}{*}{$\begin{array}{l}\text { Preçc } \\
\text { total }\end{array}$} \\
\hline & & & & Unit. & Total & Unit. & Total & Unit. & Total & \\
\hline 1 & $\begin{array}{c}\text { Formas de compensado plastificado } 10 \text { mm - uso } \\
\text { geral - utilização de } 3 \text { vezes - confecção, instalação } \\
\text { e retirada }\end{array}$ & $m^{2}$ & $\begin{array}{l}\text { న } \\
\text { षे }\end{array}$ & $\begin{array}{l}\infty \\
0 \\
\infty \\
\stackrel{\infty}{\sim} \\
\underset{\sim}{\infty}\end{array}$ & 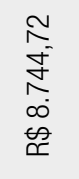 & 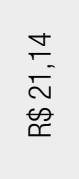 & 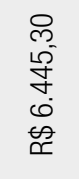 & $\begin{array}{l}\text { 巳 } \\
\text { ‡ } \\
\text { ॄि }\end{array}$ & 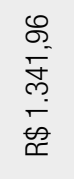 & 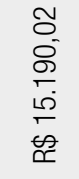 \\
\hline 2 & $\begin{array}{c}\text { Armação em aço CA-50 - fornecimento, } \\
\text { preparo e colocação }\end{array}$ & $\mathrm{kg}$ & \begin{tabular}{l}
\multirow{\leftarrow}{*}{} \\
$\stackrel{0}{m}$ \\
$\underset{n}{n}$
\end{tabular} & 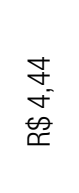 & 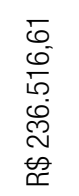 & 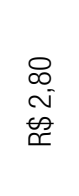 & 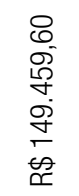 & $\begin{array}{l}1 \\
\infty\end{array}$ & $\begin{array}{l}1 \\
\infty\end{array}$ & 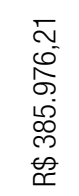 \\
\hline
\end{tabular}

Concreto para bombeamento $f_{c k}=25 \mathrm{MPa}-1116263$

3 confecção em central dosadora de $40 \mathrm{~m}^{3} / \mathrm{h}$ - areia e brita comerciais

\begin{tabular}{|c|c|c|}
\hline 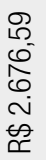 & $\begin{array}{l}\text { ఫ } \\
\text { స్ } \\
\text { } \\
\text { జ̂ }\end{array}$ & $\begin{array}{l}\text { రీ } \\
\text { లె } \\
0 \\
0 \\
0 \\
\text { के }\end{array}$ \\
\hline
\end{tabular}

Total Material: $\mathrm{R} \$ 303.081,38$ Total Mão de Obra: $\mathrm{R} \$ 158.581,49$ Total Equipamento: $\mathrm{R} \$ 47.375,59$ TOTAL: $\mathrm{R} \$ 461.662,87$

Fonte: Elaborado pelo autor 


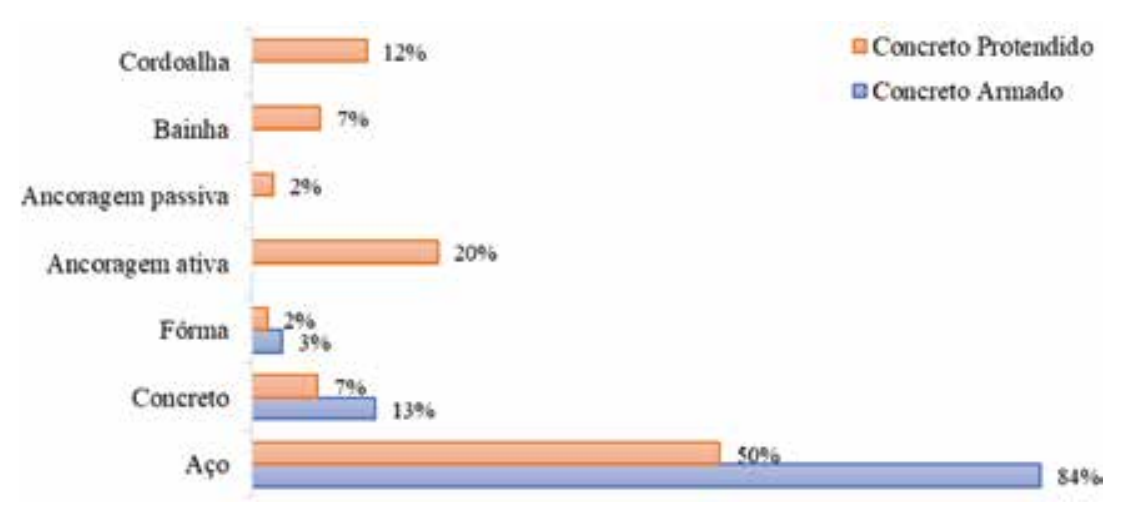

Fonte: Elaborado pelo autor

Figura 11

Comparativo dos custos

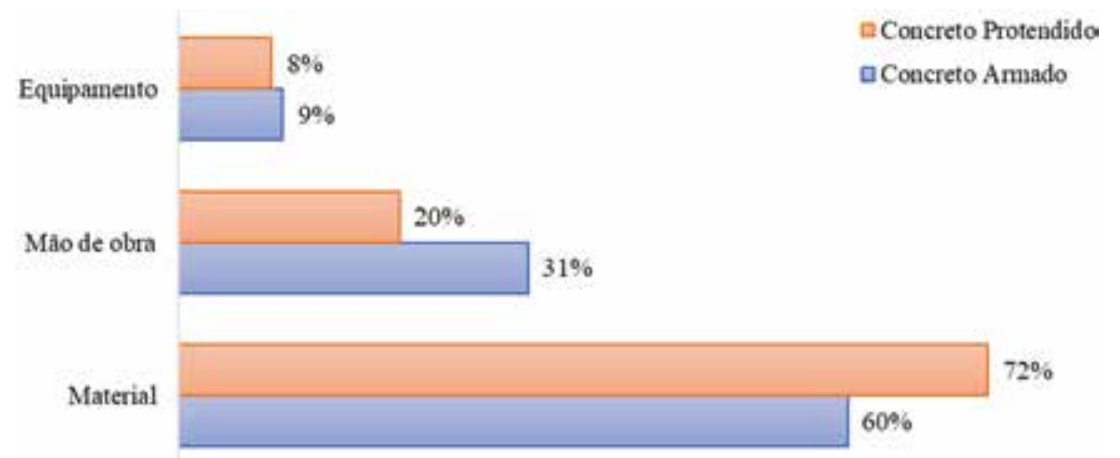

Fonte: Elaborado pelo autor

Figura 12

Comparativo dos insumos

(Equação 1); segundo, pelo uso de um concreto com maior resistência, exigido para o concreto protendido; terceiro, o uso seção transversal menor.

\section{CONCLUSÕES}

Por fim, conclui-se que o uso do concreto protendido como material de construção para longarinas de pontes com vãos até 19 metros, conforme o estudo de caso em questão, ainda apresenta custos diretos superiores aos custos do concreto armado convencional. Como desvantagem, o concreto protendido exige o uso de mão de obra mais especializada e o uso

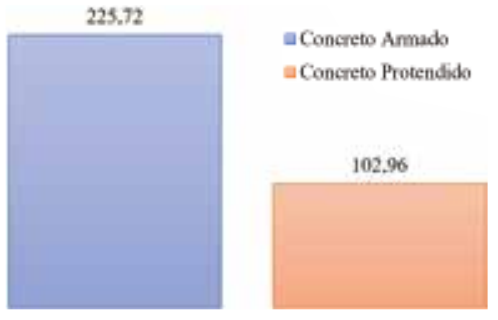

Fonte: Elaborado pelo autor

Figura 13

Volume de concreto $\left[\mathrm{m}^{3}\right]$

de elementos construtivos onerosos, como, por exemplo, a ancoragem e os cabos de protensão. Outrossim, pode-se citar como vantagens a economia nos quantitativos de aço (armadura passiva), economia nos quantitativos do concreto e uma durabilidade maior do elemento estrutural devido ao $f_{c k}$ maior.

Ademais, o custo direto é um parâmetro que norteia a viabilidade econômica de uma obra ou serviço de engenharia e deve ser considerado concomitantemente com outros fatores que compõe o preço de um empreendimento, como: custos indiretos (escoramento, içamento, consultoria, etc.); a composição do Benefícios de Despesas Indiretas (BDI); custo manutenção da estrutura; custo dos possíveis impactos ambientais; dentre outros. Logo, cabe ao engenheiro cidadão ponderar sobre esses aspectos, e tantos outros, no instante em que delibera sobre obras de infraestrutura, como é o caso das pontes.

\section{REFERÊNCIAS BIBLIOGRÁFICAS}

[01] AGÊNCIA TOCANTINENSE DE TRANSPORTE E OBRAS (AGETO): Projeto Executivo de Engenharia - Avenidas NS-15 e L0-13- Interligação. Palmas: SEINFRA, 2015. v. 8.

[02] ASSOCIAÇÃO BRASILEIRA DE NORMAS TÉCNICAS. NBR 6118: Projeto de estruturas de concreto - Procedimento. Rio de Janeiro: ABNT, 2014.238 p.

[03] ASSOCIAÇÃO BRASILEIRA DE NORMAS TÉCNICAS. NBR 7188: Carga móvel rodoviária e de pedestres em pontes, viadutos, passarelas e outras estruturas. Rio de Janeiro: ABNT, 2013.14 p.

[04] DEBS, Mounir Khalil El; TAKEYA, Toshiaki. Introdução às Pontes de Concreto. São Carlos: UFSC, 2007. 221 p. Disponível em: http://wwwp.feb.unesp.br/pbastos/ pontes/Apost.\%20Pontes\%20-\%20Mounir-Takeya.pdf. Acesso em: 29 maio 2020.

[05] DEPARTAMENTO NACIONAL DE INFRAESTRUTURA DE TRANSPORTES. SICRO: Sistema de Custos Referenciais de Obras - Tocantins, março 2017. Brasília: DNIT, 2017. v. 5. Disponível em: http://www.dnit.gov.br/custos-e-pagamentos/sicro/norte/tocantins/2017/marco/marco-2017. Acesso em: 29 maio 2020. 